\title{
Bet hedging in a warming ocean: predictability of maternal environment shapes offspring size variation in marine sticklebacks
}

\author{
LISA N. S. SHAMA \\ Coastal Ecology Section, Alfred-Wegener-Institut Helmholtz-Zentrum für Polar-und Meeresforschung, Wadden Sea Station Sylt, \\ List, Germany
}

\begin{abstract}
Bet hedging at reproduction is expected to evolve when mothers are exposed to unpredictable cues for future environmental conditions, whereas transgenerational plasticity (TGP) should be favoured when cues reliably predict the environment offspring will experience. Since climate predictions forecast an increase in both temperature and climate variability, both TGP and bet hedging are likely to become important strategies to mediate climate change effects. Here, the potential to produce variably sized offspring in both warming and unpredictable environments was tested by investigating whether stickleback (Gasterosteus aculeatus) mothers adjusted mean offspring size and within-clutch variation in offspring size in response to experimental manipulation of maternal thermal environment and predictability (alternating between ambient and elevated water temperatures). Reproductive output traits of F1 females were influenced by both temperature and environmental predictability. Mothers that developed at ambient temperature $\left(17^{\circ} \mathrm{C}\right)$ produced larger, but fewer eggs than mothers that developed at elevated temperature $\left(21^{\circ} \mathrm{C}\right)$, implying selection for different-sized offspring in different environments. Mothers in unpredictable environments had smaller mean egg sizes and tended to have greater within-female egg size variability, especially at $21^{\circ} \mathrm{C}$, suggesting that mothers may have dynamically modified the variance in offspring size to spread the risk of incorrectly predicting future environmental conditions. Both TGP and diversification influenced F2 offspring body size. F2 offspring reared at $21{ }^{\circ} \mathrm{C}$ had larger mean body sizes if their mother developed at $21^{\circ} \mathrm{C}$, but this TGP benefit was not present for offspring of $17{ }^{\circ} \mathrm{C}$ mothers reared at $17{ }^{\circ} \mathrm{C}$, indicating that maternal TGP will be highly relevant for ocean warming scenarios in this system. Offspring of variable environment mothers were smaller but more variable in size than offspring from constant environment mothers, particularly at $21^{\circ} \mathrm{C}$. In summary, stickleback mothers may have used both TGP and diversified bet-hedging strategies to cope with the dual stress of ocean warming and environmental uncertainty.
\end{abstract}

Keywords: climate change, diversified bet hedging, egg size plasticity, environmental variability, Gasterosteus aculeatus, maternal effects, paternal effects, transgenerational plasticity

Received 9 April 2015; revised version received 6 July 2015 and accepted 7 July 2015

\section{Introduction}

Population persistence in changing environments requires that organisms adjust their phenotypes to match local conditions. This can be achieved by rapid evolution (genetic tracking) and/or adaptive phenotypic plasticity (Chevin et al., 2010). Adaptive phenotypic plasticity is expected to evolve when environmental cues of future conditions are predictable or recurring (Via, 1993; Simons, 2011). Plasticity can occur both within generations (organisms respond to their immediate environment) and across generations via transgenerational plasticity (TGP). In the case of

Correspondence: Lisa N. S. Shama, tel. +49 (0)4651 956 4204, fax +49 (0)4651 956 200, e-mail: lisa.shama@awi.de
TGP, anticipatory parental effects (sensu Marshall \& Uller, 2007; Burgess \& Marshall, 2014) on offspring phenotypes will only be favoured if the parental environment is a good predictor of the environment offspring will experience (Mousseau \& Fox, 1998; Räsänen \& Kruuk, 2007). When environmental conditions vary unpredictably, and parents cannot predict their offspring's environment, the evolution of bet hedging is expected, for instance, parents should produce a range of offspring phenotypes with at least some having the optimal phenotype (Einum \& Fleming, 2004; Marshall et al., 2008; Fischer et al., 2011; Simons, 2011). Given that recent climate predictions forecast an increase in weather variability (IPCC 2012), such as more frequent and severe storms and other extreme events including heat waves, droughts and flooding (Thornton et al., 
2014), bet hedging is likely to become an increasingly important strategy to mediate some of the impacts of rapid climate change (Crean \& Marshall, 2009). Indeed, it was recently shown that projections based on mean temperature change alone differ substantially from those incorporating changes to temperature variation, and that increased variation might pose an even greater risk to species than climate warming (Vasseur et al., 2014). Nevertheless, bet hedging is currently under-represented in treatments of evolutionary responses to environmental variance (Simons, 2011).

Theoretical evidence for bet hedging at reproduction as an adaptive strategy in unpredictable environments has been established for half a century (Cohen, 1966; Seger \& Brockmann, 1987; Philippi \& Seger, 1989). Bet hedging should be advantageous because it increases geometric-mean fitness (e.g. cumulative fecundity across generations), but does so at the expense of expected fitness within a generation. Thus, bet-hedging strategies appear to be detrimental over the short-term (Slatkin, 1974; Simons, 2011). Two main forms of bet hedging are commonly recognized: conservative and diversified (Seger \& Brockmann, 1987; Philippi \& Seger, 1989; but see Olofsson et al., 2009 for a third form). Conservative bet hedging or 'playing it safe' occurs when, for example, mothers produce larger offspring than would be the optimum in a stable environment with the same long-term mean quality. This strategy can result in greater reproductive success during poor years if larger offspring are more than successful than smaller offspring in poor conditions (Einum \& Fleming, 2004). Diversified bet hedging occurs when mothers increase the phenotypic variance among individual offspring, thereby spreading the risk of reproductive failure in uncertain environments among an array of offspring phenotypes (Crean \& Marshall, 2009). There is theoretical support for both forms (Einum \& Fleming, 2004; Marshall et al., 2008), but ultimately, the relative benefits of one or the other strategy will depend on the specific offspring trait-fitness function (Smith \& Fretwell, 1974; Marshall et al., 2008). Empirical evidence for bet hedging, on the other hand, is rather scant. While there are numerous correlative studies invoking bet hedging as an explanation for within-clutch variation in offspring phenotypes (reviewed in Crean \& Marshall, 2009 and Simons, 2011), direct tests that manipulate environmental predictability are rare (but see Halpern, 2005; Manenti et al., 2014; Furness et al., 2015). Recent comparative studies of populations along gradients of environmental predictability (Morrongiello et al., 2012; Garcia-Roger et al., 2014) and direct tests of Cohen's predictions regarding propagule dormancy (Graham et al., 2014; Gremer \& Venable, 2014; Simons, 2014) highlight the importance of bet hedging as a potential mechanism for organisms to cope with increasing climate variability.

Bet hedging entails an inherent trade-off between maximizing within-generation fitness and minimizing among-generation variation in reproductive success (Marshall et al., 2008). Although evidence for paternal environment effects on offspring phenotypes is accumulating (e.g. Crean et al., 2013; Shama \& Wegner, 2014), the majority of studies have investigated how mothers deal with the challenge of managing this trade off. Within a generation, mothers maximize fitness via plasticity in the mean offspring phenotype, whereas across generations, they manage the variance in fitness via bet hedging (Crean \& Marshall, 2009). Because environmental variance is composed of both predictable and unpredictable components, the concurrent evolution of both plasticity and bet hedging is expected, although little studied (but see Simons, 2014; Furness et al., 2015). The number of studies showing changes in the mean offspring phenotype as a result of TGP has risen dramatically over the past few years (reviewed in Bonduriansky et al., 2012; Salinas et al., 2013), but very few have explicitly estimated the predictability of environmental cues (but see Galloway \& Etterson, 2007), hence the adaptive significance of this plasticity remains unclear (Burgess \& Marshall, 2011). Moreover, although correlative and comparative studies of bet hedging suggest that females can adjust the variability of offspring phenotypes (see references listed above), experiments that manipulate maternal environmental predictability are needed to determine if mothers can dynamically modify this variation (Crean \& Marshall, 2009).

Optimality models predict that under constant environmental conditions, a single, optimal offspring size will be favoured, and different sizes will be optimal in different environments depending on the offspring size-fitness relationship in each environment (Marshall et al., 2008). Consistent with this, there are numerous studies showing that mothers can shift the phenotype of their offspring to match local conditions (reviewed in Burgess \& Marshall, 2014), that is, they exhibit adaptive phenotypic plasticity. When environmental conditions are good, some models predict that mothers should produce smaller, but more offspring to maximize fecundity, whereas under harsh conditions, they should produce fewer, larger offspring that are presumed to be of higher quality (Einum \& Fleming, 2004). Yet, evidence is accumulating to support the argument that 'bigger is not always better in harsh environments' (Kaplan, 1992). For example, smaller offspring may be favoured under size-selective predation, or when larger size is associated with higher physiological demands under heat stress (see Morrongiello et al., 2012 for more 
examples). When environmental conditions are unpredictable, mothers should maximize fitness by producing a range of offspring sizes in the hope that at least some will have the optimal size for local conditions. By using such a diversified bet-hedging strategy, mothers decrease the variance in fitness across years, but do so at a cost to fitness within a year, since the more offspring size varies, the more offspring that are away from the optimal size (Crean \& Marshall, 2009).

The aim of this study was to test the potential to produce variably sized offspring in both warming and unpredictable environments by investigating whether stickleback (Gasterosteus aculeatus) mothers adjust mean offspring size and within-clutch variation in offspring size in response to experimental manipulation of maternal thermal environment and predictability, in this case, varying sea surface temperatures (SST). Previous studies of this population found that elevated water temperatures $\left(21^{\circ} \mathrm{C}\right)$ simulated in accordance with a 2100 climate scenario (Sheppard, 2004) had detrimental effects on growth (Schade et al., 2014) and development (Ramler et al., 2014), in comparison to water temperatures that reflected local, ambient summer conditions $\left(17^{\circ} \mathrm{C}\right)$. Yet, when mothers were acclimated to elevated temperature during reproductive conditioning, offspring reached (relatively) larger sizes in the warmer environment as a result of maternal TGP (or anticipatory maternal effects) in response to predictable environmental cues of future water temperatures (Shama et al., 2014). But what happens when environmental cues are unpredictable, for example, when seas surface temperatures change by several degrees over short time periods in response to variable weather patterns and extreme events such as heat waves (Thornton et al., 2014; Vasseur et al., 2014)? When environmental cues are unpredictable, mothers should adopt a bet-hedging strategy and produce a range of offspring sizes (Marshall et al., 2008).

In the current study, the prediction was that not only the mean but also the variance in offspring phenotypes should differ depending on maternal thermal environment and predictability. Given that previous work has also shown that stickleback mothers that developed at elevated temperature $\left(2{ }^{\circ} \mathrm{C}\right)$ produced more, but smaller eggs than mothers that developed under ambient conditions (Shama \& Wegner, 2014), the specific prediction here was that mothers acclimated to constant, but different temperatures $\left(17^{\circ} \mathrm{C}\right.$ or $\left.21^{\circ} \mathrm{C}\right)$ should produce offspring of a mean optimal size to match local conditions. Under variable environmental conditions (switching between ambient and elevated temperature), mothers should produce a range of offspring sizes, with some matching the optimal mean size for both experimental temperatures. In other words, when mothers can predict the thermal environment their offspring will experience, TGP in mean offspring size should be favoured, whereas environmental uncertainty should promote increased variance in offspring size (Crean \& Marshall, 2009; Simons, 2011).

\section{Materials and methods}

\section{Environmental predictability in the wild}

To characterize the predictability of environmental conditions that mothers and offspring experience in the wild, SST from the study area were obtained from the Coastal Observing System for Northern and Arctic Seas data web portal of the Helmholtz-Zentrum Geesthacht Zentrum für Material-und Küstenforschung (http://www.cosyna.de). Temperatures were recorded every $30 \mathrm{~min}$ from 15 March to 31 December 2012 using a Directional Waverider Buoy (Datawell bv, Haarlem, the Netherlands) located off the west coast of Sylt, Germany $\left(54^{\circ} 79^{\prime} \mathrm{N}, 8^{\circ} 27^{\prime} \mathrm{E}\right)$.

\section{Fish crosses and experimental design}

The experiment used marine three-spine sticklebacks from three generations: wild-caught grandparental fish (F0), laboratory-reared parental fish (F1) and laboratory-reared F2 offspring (Box 1). Grandparent fish originated from an oceanic population in the Sylt-Rømø Bight $\left(55^{\circ} 05^{\prime} \mathrm{N}, 8^{\circ} 39^{\prime} \mathrm{E}\right)$ that were caught by trawling in February 2012, brought to the laboratory, and held at $17{ }^{\circ} \mathrm{C}$ for 2 months during reproductive conditioning. Crosses were made over a 2-week period in May 2012 to produce $11 \mathrm{~F} 1$ families with a $17^{\circ} \mathrm{C}$ male $\times 17^{\circ} \mathrm{C}$ female thermal acclimation history. Offspring from each family were split and reared at 17 and $21^{\circ} \mathrm{C}$ (Box 1). Families were reared separately for the first 60 days posthatch. After this, juvenile F1 fish from all families within each rearing temperature were pooled, divided amongst several 25-L aquaria to reach a final density of 25-30 fish per aquarium, and reared to adulthood (see Shama et al., 2014 for details).

When the F1 fish were 10 months old, (now) adult fish from within each rearing temperature were randomly split into environmental predictability treatments and held under these conditions for another 2 months, corresponding to the period of F1 reproductive conditioning (Box 1). Specifically, fish reared at $17{ }^{\circ} \mathrm{C}$ were either maintained at a constant temperature of $17^{\circ} \mathrm{C}$ (17con), or switched weekly between 17 and $21{ }^{\circ} \mathrm{C}$ (17var). Similarly, fish reared at $21^{\circ} \mathrm{C}$ were either maintained at $21{ }^{\circ} \mathrm{C}$ (21con) or switched weekly between temperatures (21var). Fish in constant temperature treatments were also switched among aquaria of the same temperature each week to account for possible confounding effects of physically moving to different aquaria. F2 crosses were performed over a 2-week period in May 2013 to produce 38 families. Each of 19 F1 females was mated to two F1 males, one from $17^{\circ} \mathrm{C}$ and one from $21{ }^{\circ} \mathrm{C}$ (crossing methods as in Shama et al., 2014). As the focus of the study was maternal environment predictability, only males from the constant temperature treatments were used in crosses. F2 egg clutches from each family were then 
Box 1 Experimental design using 3 generations of marine sticklebacks to investigate potential transgenerational plasticity (TGP) and bet hedging in response to ocean warming and increased climate variability.

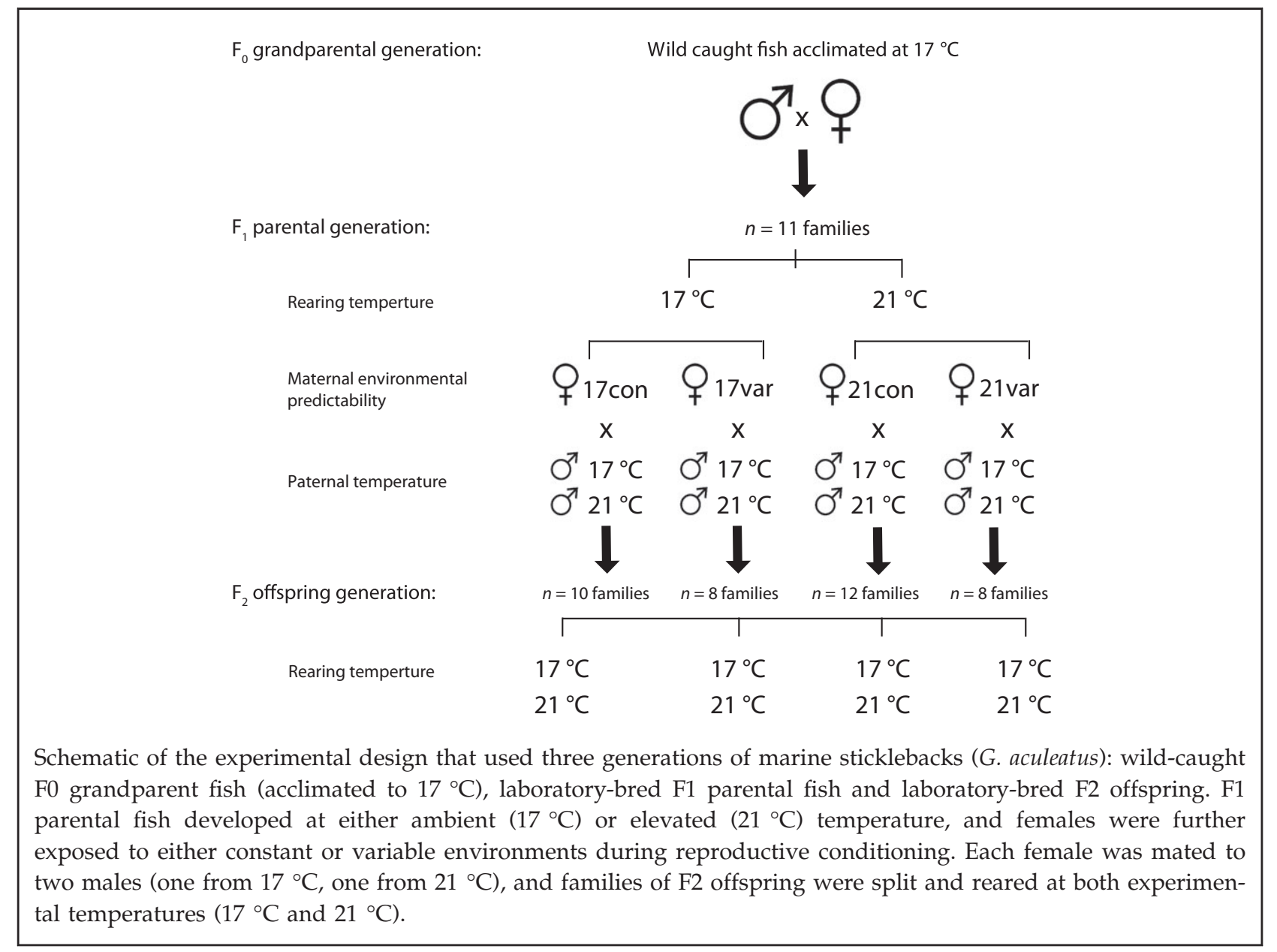

split and reared at $17^{\circ} \mathrm{C}$ and $21^{\circ} \mathrm{C}(n=76$ split clutches $/$ families in total; Box 1).

\section{Egg traits and offspring body size}

Each split clutch of eggs was photographed under a dissecting microscope for digital analyses of egg size and clutch size (using LEICA QWIN imaging software; Leica Microsystems Imaging Solutions Ltd., Cambridge, UK). Egg size was estimated by measuring the diameter $( \pm 0.01 \mathrm{~mm})$ of 20 eggs per female. The 20 measured eggs were chosen based on the clarity of their outer perimeter in the photographs. Clutch size was estimated as the total number of eggs per female. Splitclutches were placed individually in 1-L glass beakers containing filtered seawater and an air supply, and beakers were held in water baths heated to either $17^{\circ} \mathrm{C}$ or $21^{\circ} \mathrm{C}$. Hatching success was estimated as the proportion of hatchlings from each split clutch (no. hatchlings/no. eggs). Hatchlings were held in beakers for the first 30 days, and water in the beakers was changed every week. At 14 days posthatch, hatchling densities were reduced to approximately 10 offspring per beaker.
At 30 days posthatch, 10 randomly chosen offspring from each split clutch were photographed under a dissecting microscope for digital analysis of body size (standard length $\pm 0.01 \mathrm{~mm}$, using LEICA QWIN). At this point, the 10 offspring were transferred to a 2-L aquarium connected to a flow-through seawater system set at either $17^{\circ} \mathrm{C}$ or $21^{\circ} \mathrm{C}$ for another 60 days. At 60 and 90 days posthatch, standard length was again measured on the 10 offspring per family by digital photography. Throughout the experiment, juvenile fish were fed daily with live Artemia sp. nauplii ad libitum.

\section{Data analyses}

Correlograms were used to assess the predictability of SST in the wild (see also Burgess \& Marshall, 2011). Correlograms are plots of the autocorrelation between successive terms in a data series, in this case, a time series of water temperature data. Autocorrelation measures the dependence of values in a series on the values before it at a distance of $k$ lags, and can be used to show, for example, whether water temperature on a given day is a good predictor of water temperature at some 
time point in the future (Burgess \& Marshall, 2011, 2014). Daily means for SST from 01 May through 31 August 2012 ( $n=123$ days $)$ were used in the analyses, and reflect the time period that fish from the grandparental population were present and potentially reproductive in the Sylt-Rømø Bight (L.N.S. Shama, personal observation). The raw SST data did not exhibit stationarity (Shapiro-Wilk normality test, $W=0.914, P<0.001$ ), so were first detrended by taking the residuals of a linear model of SST as a function of time (adjusted $R^{2}=0.927$; Legendre \& Legendre, 1998). After detrending, the data exhibited stationarity (Shapiro-Wilk normality test, $W=0.987, P=0.319$ ) and autocorrelations were calculated using the acf function within the R package 'TSA'.

Generalized linear mixed effects models (GLMMs) were used to quantify the effects of temperature and environmental predictability on traits related to reproductive output of F1 parental fish (egg size, clutch size and hatching success) and F2 offspring body size. Body size is a decisive component of fitness for sticklebacks, influencing, for example, fecundity in females and success in fights for territories and sperm competition in males (Dufresne et al., 1990). To show that the relationship between size and fitness also holds for the parental fish used here, the effect of female size on egg traits related to reproductive output was also analysed. Specifically, egg size and clutch size were modelled with female identity as a random effect, female size and clutch size (or egg size) as covariates, and maternal developmental temperature and environmental predictability (plus their interaction) as fixed effects. Offspring body size at 30, 60 and 90 days was modelled with family as a random effect, density, egg size and female size as covariates, and offspring rearing temperature, parental (sire and dam) developmental temperatures and environmental predictability (and their interactions) as fixed effects. Since only sires from the constant temperature treatments were used in crosses, no sire by environmental predictability term was included in the models. Egg size, clutch size and offspring body size were modelled with Gaussian errors using Maximum Likelihood within the lme function of the $\mathrm{R}$ package 'nlme'.

Given the potential for maternal environment unpredictability to lead to increased variation in offspring size, and hence, heterogeneity of variances among predictability treatment groups, homogeneity of variances was first checked using Levene's test. Each response variable with significant heterogeneity of variances was then modelled using the weights function (variance classes) that allows unequal variances across groups in lme. Moreover, given that the focus of the study was not only response means but also their variance, and that standard deviations and variances typically show strong relationships with means (see Crean \& Marshall, 2009), the coefficient of variation (CV) of egg size and offspring body size were also modelled using lme. Two levels of egg size variability were estimated using the CV: within-female variability (within-female egg size CV averaged across all females in a treatment) and among-female variability $(\mathrm{CV}$ of mean egg size per female in each treatment; see also Morrongiello et al., 2012). Note: only withinfemale egg size variability was modelled using lme, as there was only one value per treatment (i.e. no error) for amongfemale variability. Differences between within- and amongfemale variability per treatment were tested with $t$-tests. Hatching success was modelled with the same fixed effects as above, but with binomial errors, family as a random effect, and an individual-level random effect to account for overdispersion using glmer implemented in the $\mathrm{R}$ package 'Ime4'. All models were fit using individuals, that is, individual eggs for analyses of egg size and hatching success, and individual fish for offspring body size. For graphical display, offspring body size at 30,60 and 90 days are shown as residual body size (standard length corrected for density). All analyses were run in the $\mathrm{R}$ statistical environment ( $\mathrm{R}$ Development Core Team, 2011).

\section{Results}

\section{Environmental predictability}

Sea surface temperature on any particular day was a good predictor of water temperature up to 9 days in the future (Fig. 1). The correlogram shows a significant positive correlation between SSTs for 9 days, but the
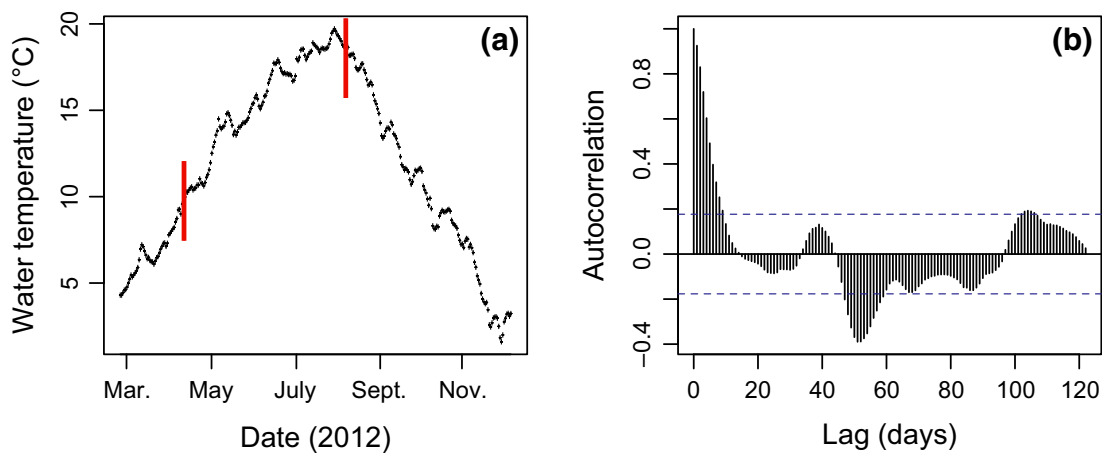

Fig. 1 Predictability of temperature in the wild reflected as (a) sea surface temperature (SST) profile, and (b) correlogram showing the autocorrelation of values in the series on values found at a distance of $k$ lags ( 1 lag $=1$ day). Red bars (a) delineate the time span within the annual SST profile (May through August) from which daily means were used in the analysis. Dashed blue lines in the correlogram (b) approximate $95 \%$ confidence limits for an independent data series for which the autocorrelation is zero. 
strength of the autocorrelation decreases after 6 days. The significant negative correlation at 50 days and nearly significant correlations at approximately 70, 90 and 105 days likely reflect abrupt changes in temperature direction (step changes; Legendre \& Legendre, 1998) within the data series (Fig. 1b). For this population of sticklebacks, eggs that develop at $17^{\circ} \mathrm{C}$ hatch after 7 days, and those that develop at $21^{\circ} \mathrm{C}$ hatch after 5 days (see below). A significant autocorrelation of SST for 6-9 days indicates that the environment into which mothers lay eggs is a good predictor of the conditions larvae will experience during very early life.

\section{Maternal environment predictability and reproductive output}

Mean egg size was significantly influenced by clutch size and the interaction between maternal development temperature and environmental predictability (Table 1). Mothers acclimated to $17^{\circ} \mathrm{C}$ variable conditions (17var) produced smaller eggs than mothers in 17 con, whereas eggs from $21^{\circ} \mathrm{C}$ mothers had similar mean sizes regardless of environmental variability (Fig. 2a). Overall, eggs of $17^{\circ} \mathrm{C}$ mothers were larger than those from $21^{\circ} \mathrm{C}$ mothers (ANOva: dam ${ }^{\circ} \mathrm{C}$

Table 1 Linear mixed effects models of mean egg size, the coefficient of variation (CV) of egg size (within-female variability), and clutch size of stickleback (Gasterosteus aculeatus) females depicting the influence of maternal developmental temperature (dam ${ }^{\circ} \mathrm{C}$ ) and environmental predictability (predictability)

\begin{tabular}{|c|c|c|c|c|c|c|c|c|c|}
\hline \multirow[b]{2}{*}{ Source } & \multicolumn{3}{|c|}{ Mean egg size } & \multicolumn{3}{|c|}{ CV of egg size } & \multicolumn{3}{|c|}{ Clutch size } \\
\hline & denDF & $F$ & $P$ & denDF & $F$ & $P$ & denDF & $F$ & $P$ \\
\hline Intercept & 361 & 20549.198 & $<0.001$ & 14 & 596.132 & $<0.001$ & 13 & 198.503 & $<0.001$ \\
\hline Female size & 13 & 0.258 & 0.620 & 14 & 0.802 & 0.386 & 13 & 0.443 & 0.517 \\
\hline Clutch size & 13 & 13.432 & 0.003 & & & & & & \\
\hline Egg size & & & & & & & 13 & 10.531 & 0.006 \\
\hline $\operatorname{Dam}^{\circ} \mathrm{C}$ & 13 & 3.830 & 0.072 & 14 & 0.973 & 0.341 & 13 & 1.283 & 0.278 \\
\hline Predictability & 13 & 0.687 & 0.422 & 14 & 0.552 & 0.470 & 13 & 1.015 & 0.332 \\
\hline Dam ${ }^{\circ} \mathrm{C} \times$ Predictability & 13 & 5.236 & 0.040 & 14 & 0.161 & 0.694 & 13 & 6.996 & 0.020 \\
\hline
\end{tabular}

Numerator degrees of freedom were 1 in all cases. denDF denotes denominator degrees of freedom. Significant terms are highlighted in bold.
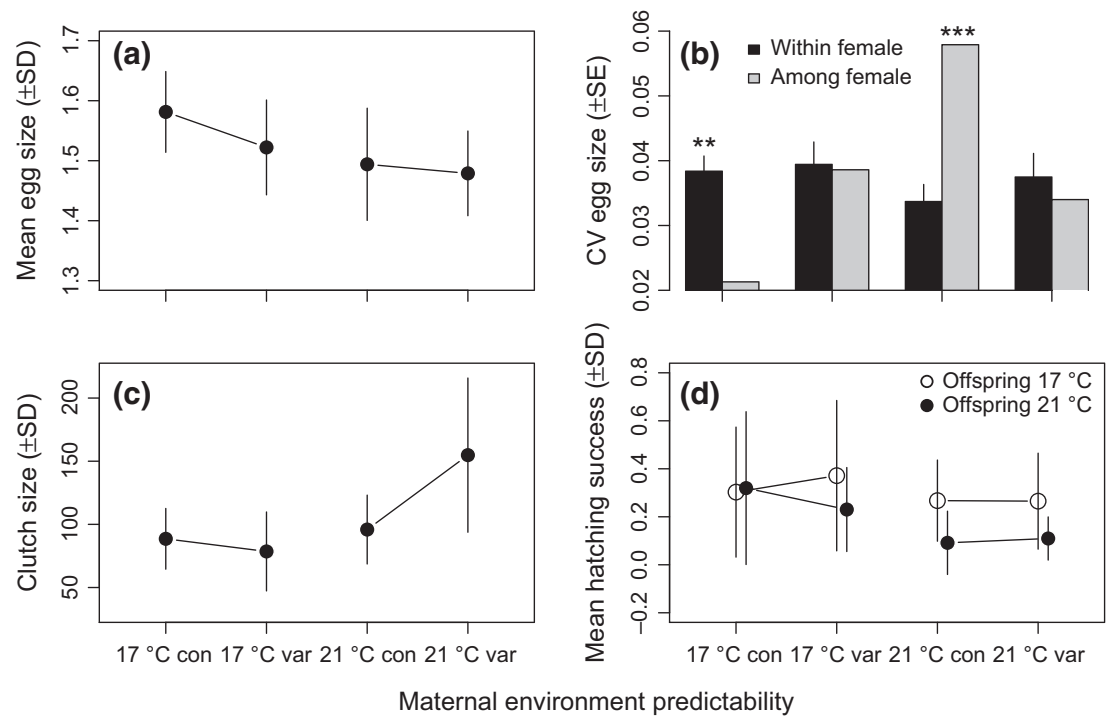

Fig. 2 Reproductive output traits of female sticklebacks (Gasterosteus aculeatus) for each maternal temperature and predictability combination. Treatment combinations are depicted as $17 \mathrm{con}\left(17^{\circ} \mathrm{C}\right.$ constant), 17 var $\left(17^{\circ} \mathrm{C}\right.$ variable), 21 con $\left(21^{\circ} \mathrm{C}\right.$ constant $)$ and 21 var $\left(21{ }^{\circ} \mathrm{C}\right.$ variable). (a) mean egg size, (b) coefficient of variation (CV) of egg size, shown as within-female variability (black bars) and among-female variability (grey bars), (c) clutch size and (d) mean hatching success (hatching proportion) for offspring reared at $17{ }^{\circ} \mathrm{C}$ (open circles) and $21^{\circ} \mathrm{C}$ (closed circles). Points or bars reflect means for all females within a treatment ( $\pm \mathrm{SD}$ or SE); lines join maternal thermal environments; $* * P<0.01, * * * P<0.001$. 
Table 2 Generalized linear mixed effect model (GLMM) for Gasterosteus aculeatus hatching success showing the influence of offspring rearing temperature (offspring ${ }^{\circ} \mathrm{C}$ ), parental developmental temperature $\left(\operatorname{dam}{ }^{\circ} \mathrm{C}\right.$, sire ${ }^{\circ} \mathrm{C}$ ) and maternal environment predictability (predictability)

\begin{tabular}{|c|c|c|c|c|}
\hline Random effects & & Variance & & SD \\
\hline Family (intercept) & & 5.589 & & 2.364 \\
\hline Hatch (intercept) & & 0.007 & & 0.086 \\
\hline Fixed effects & Estimate & SE & $z$ value & $\begin{array}{l}\operatorname{Pr} \\
(>|z|)\end{array}$ \\
\hline (Intercept) & 6.267 & 14.817 & 0.423 & 0.672 \\
\hline Egg size & -2.849 & 7.125 & -0.400 & 0.689 \\
\hline Female size & -0.057 & 0.146 & -0.387 & 0.699 \\
\hline Offspring ${ }^{\circ} \mathrm{C}$ & -0.049 & 0.058 & -0.857 & 0.392 \\
\hline $\operatorname{Dam}^{\circ} \mathrm{C}$ & -0.757 & 1.486 & -0.510 & 0.610 \\
\hline Sire ${ }^{\circ} \mathrm{C}$ & -1.233 & 1.135 & -1.086 & 0.277 \\
\hline Predictability & 0.137 & 1.225 & 0.112 & 0.911 \\
\hline Offspring $\times$ Dam ${ }^{\circ} \mathrm{C}$ & -1.893 & 0.087 & -21.809 & $<0.001$ \\
\hline Offspring $\times$ Sire ${ }^{\circ} \mathrm{C}$ & 0.444 & 0.075 & 5.899 & $<0.001$ \\
\hline Dam $\times$ Sire ${ }^{\circ} \mathrm{C}$ & 1.249 & 1.562 & 0.800 & 0.424 \\
\hline $\begin{array}{l}\text { Offspring }{ }^{\circ} \mathrm{C} \times \\
\text { Predictability }\end{array}$ & -1.408 & 0.075 & -18.649 & $<0.001$ \\
\hline $\begin{array}{l}\text { Dam }^{\circ} \mathrm{C} \times \\
\text { Predictability }\end{array}$ & -0.963 & 1.630 & -0.591 & 0.555 \\
\hline $\begin{array}{l}\text { Offspring } \times \text { Dam } \times \\
\text { Sire }{ }^{\circ} \mathrm{C}\end{array}$ & -0.005 & 0.095 & -0.052 & 0.958 \\
\hline $\begin{array}{l}\text { Offspring } \times \text { Dam } \\
{ }^{\circ} \mathrm{C} \times \text { Predictability }\end{array}$ & 1.859 & 0.099 & 18.736 & $<0.001$ \\
\hline
\end{tabular}

Model fit with individual-level variation (accounting for overdispersion) by the Laplace approximation and a binomial error distribution using glmer implemented in the $\mathrm{R}$ package lme4 (R Development Core Team, 2011). SD and SE denote standard deviation and standard error, respectively. Significant terms are highlighted in bold.

$\left.F_{1,17}=5.308 ; P=0.034\right)$. The variance in mean egg size differed among treatment groups (dam ${ }^{\circ} \mathrm{C} \times$ predictability: Levene's Test $F_{3,376}=6.910 ; P<0.001$ ), so mean egg size was modelled using the variance classes function in lme.

Within-female egg size variability (CV of egg size), however, was not significantly influenced by maternal temperature or environmental predictability (Table 1). Yet, there was a nonsignificant trend of higher withinfemale $\mathrm{CVs}$ of egg size in variable environments, especially for eggs of $21{ }^{\circ} \mathrm{C}$ mothers (Fig. 2b). A post hoc power analysis using the 'pwr' package in $\mathrm{R}$ revealed that Cohen's $d$ for both maternal temperatures combined was 0.423 (calculated using the mean and standard deviation of egg size CV in constant and variable environments), which represents a large effect size. Splitting egg size CVs by maternal temperature, however, showed that Cohen's $d$ at $17^{\circ} \mathrm{C}$ was 0.1718 , but was 0.5506 at $21{ }^{\circ} \mathrm{C}$. Nevertheless, a linear model approach using three model terms $\left(\mathrm{dam}^{\circ} \mathrm{C} \times\right.$ predictability) showed that the power of the experiment using $n=19$ females was 0.5333 , and $n=30$ females would have been necessary to reach a power level above 0.800 (Cohen, 1988). Among-female egg size variability differed significantly from within-female variability in constant environments, but not in variable environments ( $t$-tests: 17 con $t=7.303 ; P=0.002$, 21con $t=-9.199 ; \quad P<0.001)$. Among-female variability for egg size was highest for 21con mothers, and lowest for 17 con mothers, with mothers in variable environments showing similar $\mathrm{CV}$ values (Fig. $2 b$ ).

Mean clutch size differed significantly among maternal temperature and predictability treatments, and traded-off with egg size (Table 1). Mothers in 21var environments produced larger clutches than mothers in 21con, whereas $17^{\circ} \mathrm{C}$ mothers produced clutches of similar size in both predictability treatments (Fig. 2c). Mean clutch size was inversely related to mean egg size, although 21var mothers produced much larger clutches without a correspondingly large reduction in mean egg size (Fig. 2a). In other words, 21var mothers produced eggs of approximately the same size as their constant environment counterparts despite having larger clutches, and this difference was not driven by female size ( $P>0.05$ for all egg traits; Table 1$)$. There was also no significant difference in female size among acclimation treatments (ANOvA: dam ${ }^{\circ} \mathrm{C} F_{1,14}=1.611$; $P=0.225$, predictability $F_{1,14}=0.058 ; P=0.814$, dam ${ }^{\circ} \mathrm{C} \times$ predictability $\left.F_{1,14}=0.034, P=0.857\right)$.

Hatching success varied with offspring environment, maternal and paternal developmental temperature and environmental predictability (Table 2). Mean time to hatching was $7.32 \pm 0.48$ days at $17^{\circ} \mathrm{C}$ and $5.23 \pm 0.51$ days at $21^{\circ} \mathrm{C}$. Eggs from 17var mothers had lower hatching success at $21^{\circ} \mathrm{C}$ (offspring temperature), but higher hatching success at $17^{\circ} \mathrm{C}$, whereas eggs from 17 con mothers had similar hatching success at both temperatures (Fig. 2d). Overall, eggs from $21^{\circ} \mathrm{C}$ mothers had higher hatching success at $17{ }^{\circ} \mathrm{C}$ than at $21^{\circ} \mathrm{C}(26.65 \%$ vs. $9.87 \%)$, but there was no influence of maternal environmental predictability at either offspring temperature. That is, environmental variability only affected the hatching success of eggs from $17{ }^{\circ} \mathrm{C}$ mothers, and eggs from $21^{\circ} \mathrm{C}$ mothers were more robust to temperature variability.

\section{Maternal environment effects on offspring body size}

Density had significant effects on offspring body size (Table 3). Offspring in families with higher densities reached smaller body sizes. Mean density per family was 8.97 fish at $17^{\circ} \mathrm{C}$ and 7.20 fish at $21^{\circ} \mathrm{C}$, but the 
Table 3 Linear mixed effects models for stickleback (Gasterosteus aculeatus) mean body size at 30, 60 and 90 days posthatch depicting the influence of offspring rearing temperature (offspring ${ }^{\circ} \mathrm{C}$ ), parental developmental temperatures $\left(\right.$ dam ${ }^{\circ} \mathrm{C}$, sire ${ }^{\circ} \mathrm{C}$ ) and maternal environment predictability (predictability)

\begin{tabular}{|c|c|c|c|c|c|c|c|c|c|}
\hline \multirow[b]{2}{*}{ Source } & \multicolumn{3}{|c|}{ Size 30 days } & \multicolumn{3}{|c|}{ Size 60 days } & \multicolumn{3}{|c|}{ Size 90 days } \\
\hline & denDF & $F$ & $P$ & denDF & $F$ & $P$ & denDF & $F$ & $P$ \\
\hline Intercept & 314 & 25742.25 & $<0.001$ & 314 & 64844.75 & $<0.001$ & 306 & 83721.79 & $<0.001$ \\
\hline Density & 314 & 27.79 & $<0.001$ & 314 & 305.01 & $<0.001$ & 306 & 396.74 & $<0.001$ \\
\hline Egg size & 24 & 14.17 & 0.001 & 24 & 4.82 & 0.038 & 25 & 0.73 & 0.400 \\
\hline Female size & 24 & 2.65 & 0.116 & 24 & 5.22 & 0.031 & 306 & 4.35 & 0.038 \\
\hline Offspring ${ }^{\circ} \mathrm{C}$ & 314 & 4.84 & 0.029 & 314 & 71.16 & $<0.001$ & 306 & 182.12 & $<0.001$ \\
\hline Dam ${ }^{\circ} \mathrm{C}$ & 24 & 5.98 & 0.022 & 24 & 23.68 & $<0.001$ & 25 & 16.94 & $<0.001$ \\
\hline Sire ${ }^{\circ} \mathrm{C}$ & 24 & 5.27 & 0.031 & 24 & 0.05 & 0.824 & 25 & 1.16 & 0.291 \\
\hline Predictability & 24 & 1.48 & 0.236 & 24 & 14.16 & 0.001 & 25 & 9.76 & 0.005 \\
\hline Offspring $\times$ Dam ${ }^{\circ} \mathrm{C}$ & 314 & 0.61 & 0.436 & 314 & 2.19 & 0.140 & 306 & 5.53 & 0.019 \\
\hline Offspring $\times$ Sire ${ }^{\circ} \mathrm{C}$ & 314 & 0.14 & 0.714 & 314 & 4.45 & 0.036 & 306 & 2.14 & 0.144 \\
\hline Dam $\times$ Sire ${ }^{\circ} \mathrm{C}$ & 24 & 0.03 & 0.862 & 24 & 0.06 & 0.810 & 25 & 1.12 & 0.300 \\
\hline Offspring $\times$ Predictability & 314 & 2.77 & 0.097 & 314 & 2.29 & 0.131 & 306 & 0.74 & 0.390 \\
\hline Dam ${ }^{\circ} \mathrm{C} \times$ Predictability & 24 & 4.76 & 0.039 & 24 & 6.68 & 0.016 & 25 & 2.57 & 0.122 \\
\hline Offspring $\times$ Dam $\times$ Sire ${ }^{\circ} \mathrm{C}$ & 314 & 0.40 & 0.527 & 314 & 0.41 & 0.523 & 306 & 0.72 & 0.397 \\
\hline Offspring $\times$ Dam ${ }^{\circ} \mathrm{C} \times$ Predictability & 314 & 1.62 & 0.204 & 314 & 2.23 & 0.136 & 306 & 0.24 & 0.625 \\
\hline
\end{tabular}

Body size was measured as standard length $(\mathrm{mm})$ at 30, 60 and 90 days posthatch. Numerator degrees of freedom were 1 in all cases. denDF denotes denominator degrees of freedom. Significant terms are highlighted in bold.

range of densities per family in the different rearing temperatures overlapped (Fig. S1). Differences in densities between rearing temperatures stem from differences in hatching success (lower hatching success at $21^{\circ} \mathrm{C}$ ). Nevertheless, any growth advantages of lower densities at $21^{\circ} \mathrm{C}$ would only dampen the size differences between rearing temperatures (see below). Moreover, density $\times$ offspring ${ }^{\circ} \mathrm{C}$ interactions were not significant at 30 days $\left(F_{1,349}=3.406 ; P=0.066\right), 60$ days $\left(F_{1,349}=1.479 ; \quad P=0.225\right)$ or 90 days $\left(F_{1,342}=0.004\right.$; $P=0.949$ ), indicating that any potential effects of density on offspring body size were the same in both temperatures (Fig. S1). Egg size and female size influenced offspring body size (Table 3), but these effects were the same in both maternal and offspring temperatures (egg size/female size $\times$ dam ${ }^{\circ} \mathrm{C} /$ offspring ${ }^{\circ} \mathrm{C}$ always $P>0.05)$.

Variances among treatment groups were not homogeneous for offspring body size at 30,60 or 90 days (Levene's test 30 days: $F_{7,345}=3.896 ; \quad P<0.001$, 60 days: $\quad F_{7,345}=5.207 ; \quad P<0.001, \quad 90$ days: $\left.F_{7,338}=5.415 ; P<0.001\right)$, so size was modelled using the variance classes function in lme. At 30 days, offspring from variable environment mothers grew better at $21^{\circ} \mathrm{C}$ than at $17{ }^{\circ} \mathrm{C}$ (Fig. 3a), and this likely drove the small, overall size difference between offspring temperatures $\left(21^{\circ} \mathrm{C}>17^{\circ} \mathrm{C}\right)$ at this early stage (Table 3). The significant dam ${ }^{\circ} \mathrm{C} \times$ predictability interaction stems from the same pattern, with smaller offspring of 21var mothers when reared at $17{ }^{\circ} \mathrm{C}$. At
60 days, offspring were now larger at $17{ }^{\circ} \mathrm{C}$ than $21^{\circ} \mathrm{C}$ (Table 3), and offspring from $21{ }^{\circ} \mathrm{C}$ mothers were larger than offspring from $17{ }^{\circ} \mathrm{C}$ mothers (Fig. 3b). Overall, offspring of mothers from variable environments were smaller than those from constant environment mothers, and this difference was greater for offspring of 21 var mothers that were reared at $17^{\circ} \mathrm{C}$ (Fig. 3b). At 90 days, differences between offspring rearing temperatures were even more pronounced (Table 3 ), and the pattern of larger offspring from $21^{\circ} \mathrm{C}$ mothers and larger offspring from constant environment mothers remained (Fig. 3c). Again, this was mainly driven by smaller offspring of 21var mothers that were reared at $17^{\circ} \mathrm{C}$. Essentially, offspring of variable environment mothers suffered in terms of mean body size, and this effect was strongest for offspring of 21var mothers when they were reared in a nonmatching environment as their mothers (at $17^{\circ} \mathrm{C}$ ). These effects were already present at early growth stages (30 days), and increased over time. At 90 days, there was also evidence for maternal TGP of offspring body size in the stressful environment (offspring ${ }^{\circ} \mathrm{C} \times$ dam ${ }^{\circ} \mathrm{C}$ interaction; Table 3). That is, at $21^{\circ} \mathrm{C}$, offspring of $21^{\circ} \mathrm{C}$ mothers were larger than offspring of $17^{\circ} \mathrm{C}$ mothers, but at $17^{\circ} \mathrm{C}$, offspring reached similar sizes for both maternal developmental temperatures (Fig. 3c).

The CV of offspring body size at 30,60 and 90 days was modelled using the same random and fixed effects as mean body size (Table S1). A significant interaction between offspring ${ }^{\circ} \mathrm{C}$ and predictability was detected at 

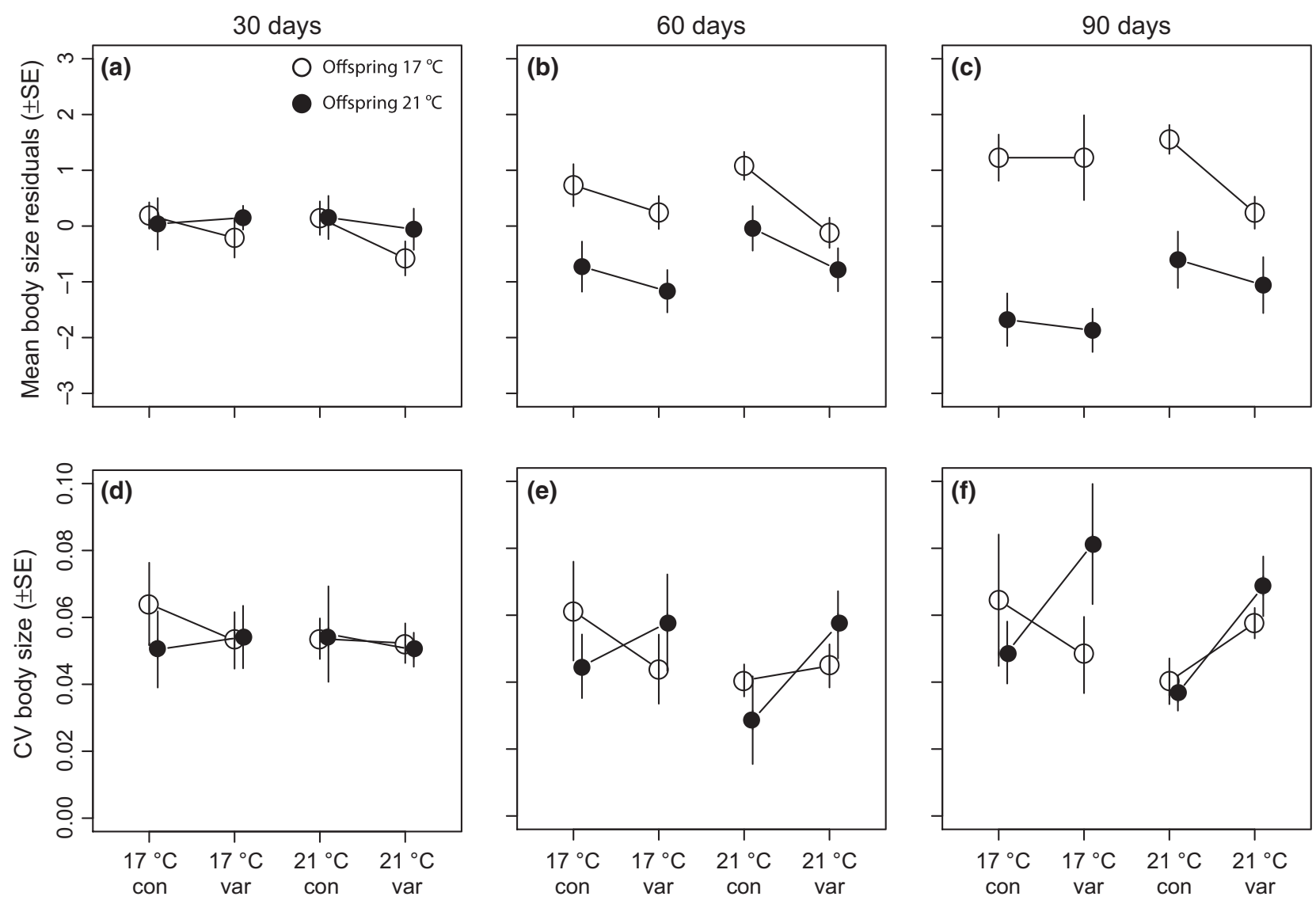

Maternal environment predictability

Fig. 3 Gasterosteus aculeatus offspring body size and coefficient of variation (CV) of offspring body size for each maternal temperature and predictability combination and reared at $17{ }^{\circ} \mathrm{C}$ (open circles) and $21^{\circ} \mathrm{C}$ (closed circles). Treatment combinations are depicted as 17 con ( $17{ }^{\circ} \mathrm{C}$ constant), $17 \operatorname{var}\left(17^{\circ} \mathrm{C}\right.$ variable), $21 \mathrm{con}\left(21^{\circ} \mathrm{C}\right.$ constant) and 21 var $\left(21^{\circ} \mathrm{C}\right.$ variable). (a-c) mean body size residuals (standard length corrected for density) at 30, 60 and 90 days posthatch, (d-f) CV of body size at 30, 60 and 90 days posthatch. Points reflect means $( \pm \mathrm{SE})$ for all families within a treatment; lines join maternal thermal environment treatments.
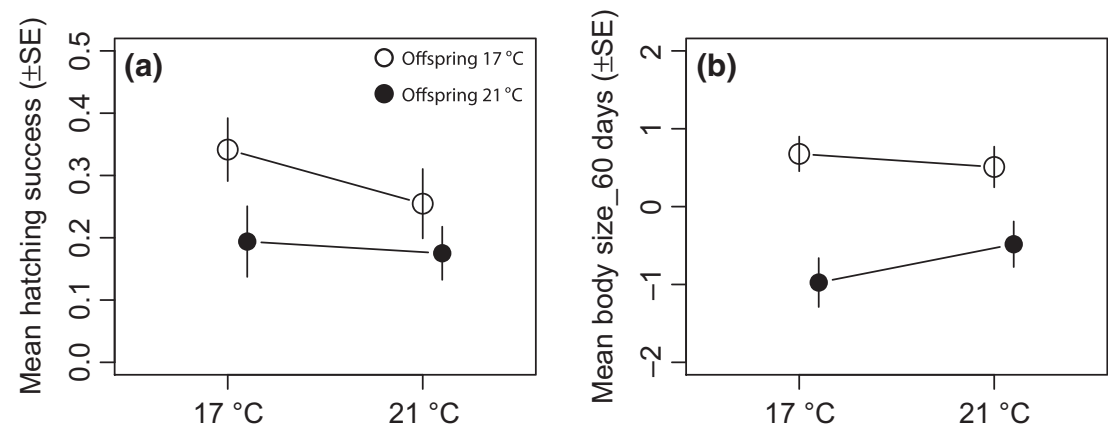

Paternal developmental temperature $\left({ }^{\circ} \mathrm{C}\right)$

Fig. 4 Paternal developmental temperature effects on Gasterosteus aculeatus offspring (a) hatching success and (b) body size at 60 days posthatch when reared at $17{ }^{\circ} \mathrm{C}$ (open circles) and $21{ }^{\circ} \mathrm{C}$ (closed circles). Hatching success is shown as hatching proportion, and body size as residuals (standard length corrected for density). Points depict means ( \pm SE) for all families within a treatment.

90 days $\left(F_{1,10}=5.663 ; P=0.039\right)$. At 90 days, offspring reared at $21{ }^{\circ} \mathrm{C}$ had higher $\mathrm{CVs}$ of body size when their mother was acclimated to a variable environment (both
17 var and 21var), whereas at $17{ }^{\circ} \mathrm{C}$, only offspring of 21var mothers had a higher CV of body size (Fig. 3f). In other words, offspring of 21var mothers had higher 
CVs of body size regardless of rearing temperature, whereas offspring of 17var mothers had higher CVs only when reared in the stressful environment. A similar pattern was also evident at 60 days (Fig. 3e), although the interaction term in the model was not significant $(P=0.152)$.

\section{Paternal environment effects}

Significant offspring $\times$ sire ${ }^{\circ} \mathrm{C}$ interactions for hatching success (Table 2) and offspring body size at 60 days (Table 3) suggest paternal TGP (Fig. 4). For hatching success, positive paternal TGP benefits were only present at $17^{\circ} \mathrm{C}$ : hatching success was higher at $17^{\circ} \mathrm{C}$ when fathers developed at $17{ }^{\circ} \mathrm{C}$, whereas hatching success at $21{ }^{\circ} \mathrm{C}$ was similar for both paternal temperatures (Fig. 4a). For offspring body size at 60 days, positive paternal TGP benefits were seen at both rearing temperatures - offspring reached a larger size at $21^{\circ} \mathrm{C}$ if their fathers developed at $21^{\circ} \mathrm{C}$, and a larger size at $17{ }^{\circ} \mathrm{C}$ if their fathers developed at $17{ }^{\circ} \mathrm{C}$ - although the effects were stronger at $21^{\circ} \mathrm{C}$ (Fig. 4b).

\section{Discussion}

Bet hedging is expected to evolve when mothers are exposed to unpredictable cues for future environmental conditions, whereas TGP should be favoured when cues reliably predict the environment offspring will experience (Simons, 2011). In line with theoretical expectations, when stickleback mothers could predict the thermal environment of their offspring, TGP benefits led to greater mean offspring sizes at elevated temperature. In varying thermal conditions, mothers may have dynamically modified the variability in offspring size, but at a cost to mean offspring size. By directly manipulating maternal thermal environment and predictability, this study demonstrates that both TGP and potential bet hedging at reproduction can play important roles in mediating some of the impacts of ocean warming and increasing climate variability. Additionally, the findings highlight the importance of considering both the mean and variance of traits responding to climate change, as these are likely to vary independently depending on the predictability of environmental cues.

\section{Environmental predictability}

Local SSTs that stickleback mothers and offspring experience in the wild are predictable for up to 9 days in the future. Since the time to hatching for this population ranges from 5 to 7 days under summer conditions, the environment into which mothers lay eggs is a good predictor of the conditions offspring will experience during embryogenesis and larval development, upon hatching, and for the first days of free-swimming life. After this initial phase, the temperature of the offspring environment becomes increasingly independent of the temperature of the maternal environment (see also Burgess \& Marshall, 2011). Here, the strength of the effects of offspring and maternal thermal environment on offspring body size was similar for the first 30 days of growth, after which offspring environment had a much stronger influence. Given that maternal environment cues are reliable predictors of the early offspring environment for this population, anticipatory maternal effects on trait means associated with reproductive output are likely to evolve (Mousseau \& Fox, 1998; Räsänen \& Kruuk, 2007; Burgess \& Marshall, 2014). Yet, variability and abrupt changes in temperature direction within the local SST profile indicate that mothers may also experience unpredictable environmental conditions (i.e. $<9$ days predictability) within the reproductive season, leading to the evolution of bet-hedging strategies (Einum \& Fleming, 2004; Marshall et al., 2008; Crean \& Marshall, 2009; Burgess \& Marshall, 2011; Fischer et al., 2011; Simons, 2011). Switching females between experimental temperatures every 7 days corresponded to the profile of temperature changes seen in the wild, and led to greater variance in offspring size, suggesting that mothers may be capable of dynamically adjusting the variability of offspring sizes depending on environmental predictability.

\section{Maternal environment predictability and reproductive output}

Stickleback mothers allocated resources to eggs differently depending on the temperature and predictability of the environment they experienced during development and reproductive conditioning. Overall, females produced larger, but fewer eggs at $17{ }^{\circ} \mathrm{C}$ and smaller, but more eggs at $21^{\circ} \mathrm{C}$, in line with other findings of egg size plasticity in response to oviposition temperature (Bownds et al., 2010; Liefting et al., 2010; Shama \& Wegner, 2014). Since reproductive output varied with maternal environment independent of female size, the plasticity of mean egg size shown here was not simply due to physiological constraints (Heath \& Blouw, 1998), but rather, more likely reflects selection for differentsized offspring in different environments (Marshall et al., 2008). If the relationship between offspring size and performance differs in each environment (Smith \& Fretwell, 1974), for example, if smaller eggs at elevated temperature are advantageous due to their lower oxygen demands (Kaplan, 1992; Kolm \& Ahnesjö, 2005; Bownds et al., 2010), then the egg size plasticity found 
here would constitute an anticipatory maternal effect or adaptive TGP (Mousseau \& Fox, 1998; Marshall \& Uller, 2007; Räsänen \& Kruuk, 2007). Still, size-related oxygen demands will depend on the proportion of yolk vs. higher respiring embryo tissue in eggs at different temperatures (Hendry \& Day, 2003), which remains to be tested for sticklebacks.

Mothers in unpredictable environments had smaller mean egg sizes and tended to have greater within-female egg size variability, especially at $21^{\circ} \mathrm{C}$ (see also Morrongiello et al., 2012), suggesting that mothers may have used a diversified bet-hedging strategy to spread the risk of incorrectly predicting future environmental conditions (Crean \& Marshall, 2009) by producing a broader range of eggs sizes (Marshall et al., 2008). Developmental instability in stressful environments has been proposed as an alternate explanation for increased within-clutch size variance (Crean \& Marshall, 2009), but was likely not the case here as mothers exposed to constant stress (21con, see below) had the lowest within-female egg size variance overall. Interestingly, mean egg size of 21 var mothers was only slightly smaller than that of 21con mothers, despite originating from much larger clutch sizes. Optimality models predict that mean egg size should decrease for 17var mothers if smaller eggs are favoured at elevated temperature, because producing a range of egg sizes that includes smaller eggs will lower the overall mean. At $21^{\circ} \mathrm{C}$, however, the mean should increase because more, larger eggs that are favoured at $17{ }^{\circ} \mathrm{C}$ should be produced (Marshall et al., 2008; Bownds et al., 2010). Here, mean egg size of 21var mothers was not greater than that of 21con mothers; hence, there was only partial size compensation at elevated temperature. Nevertheless, given the much larger clutch sizes of 21var mothers, (relative) mean egg size was indeed larger. Moreover, hatching success at elevated temperature of 21var eggs did not show the same decrease relative to 21 con as did eggs from $17{ }^{\circ} \mathrm{C}$ mothers, suggesting that possible bet hedging at elevated temperature led to (relatively) larger eggs that were more robust to stressful conditions in terms of hatching environment.

Among-female variability in egg size is expected to be higher than within-female variability when mothers experience predictable environments and can therefore provision offspring according to local optima, whereas within-female variability should be higher than among-female variability in unpredictable environments (Marshall et al., 2008; Morrongiello et al., 2012). The variability in egg size found here fits well to these predictions when mothers developed at $21{ }^{\circ} \mathrm{C}$, but less so when mothers developed at $17^{\circ} \mathrm{C}$. Selection can act differently on the two sources of female variation depending on maternal thermal environment (Marshall et al., 2008), but this cannot be confirmed by the current data, as the study cannot make adaptive inference for the variance expression found (see below). Nevertheless, females in 17con environments had the lowest among-female variability in egg size, and females in 21 con had the highest, with females in variable environments intermediate between the two. Given that prolonged exposure to $21^{\circ} \mathrm{C}$ has been shown to be a stressful environment for this population having negative effects on several traits (e.g. hatching success (Shama \& Wegner, 2014), growth (Schade et al., 2014) and development (Ramler et al., 2014), it may be that females in 21con had the greatest among-female variability in egg size because the stressful environment exacerbated individual differences among females (Charmantier \& Garant, 2005). Females in 17con experienced the least thermal stress, and females in variable environments switched between stressful and nonstressful environments. In any case, females that developed at $21^{\circ} \mathrm{C}$ fit well to theoretical predictions of diversified bet-hedging, indicating that stickleback mothers may use this as a strategy to cope with the dual stress of ocean warming and environmental uncertainty.

It is important to note that the results presented here demonstrate the expression of plasticity that can be adaptive and variance expression that can be interpreted as diversified bet hedging. Additional work would be needed to make adaptive inference in both cases. For instance, egg size-performance relationships at different temperatures and fitness benefits of smaller size at elevated temperature (e.g. higher reproductive success) need to be established. Similarly, whether offspring of mothers from variable environments grow or reproduce better in variable vs. constant environments could be determined (L.N.S. Shama, unpublished data). The finding of increased offspring size variation in unpredictable environments conforms to three of Simons' six criteria for evidence of bet hedging (Simons, 2011; see also Furness et al., 2015). Namely, a trait showing a high degree of variance was identified (offspring size), an environmental factor that leads to habitat unpredictability was identified (varying SST), and variation in the trait of interest was expressed within the same cohort while controlling for genetic and environmental sources of variation (e.g. common garden experiment using F2 families). The other three of Simons' (2011) criteria for evidence of bet hedging could not be demonstrated here: establishment of variable fitness consequences, demonstrating the advantages of these consequences under fluctuating selection, and finding a match between bet hedging trait expression and fluctuating selection. Nevertheless, the pattern found here is in the predicted direction, but more 
experiments would be needed to establish the variance expression as adaptive bet hedging.

Managing the mean and variance of offspring size (TGP and bet hedging)

Several recent climate change-related studies have demonstrated changes in the mean offspring phenotype as a result of TGP (reviewed in Munday et al., 2013; Salinas et al., 2013; Sunday et al., 2014). In most cases, offspring reared in an environment matching that of their parents showed better trait performance in terms of mean response of the variable being measured. Here, offspring reared at $21^{\circ} \mathrm{C}$ had larger mean body sizes if their mother also developed at $21^{\circ} \mathrm{C}$, whereas this TGP benefit was not present under ambient $\left(17^{\circ} \mathrm{C}\right)$ conditions, suggesting that anticipatory maternal effects will be highly relevant for climate change scenarios in this system. A similar result was found in a previous study using wild caught females that experienced acute acclimation only during reproductive conditioning (Shama et al., 2014). In that study, maternal TGP effects on offspring size were strongest at elevated temperature, but were not mediated by egg size, implying that mothers were not simply producing larger or better-provisioned offspring. Rather, mothers exposed to elevated temperatures adjusted their mitochondrial metabolic capacity, and this acute acclimatory response was transferred to offspring resulting in (relatively) better growth at higher temperatures (Munday, 2014; Shama et al., 2014).

In the present study, egg size plasticity in response to maternal developmental temperature resulted in smaller eggs at $21^{\circ} \mathrm{C}$, yet surprisingly, these smaller eggs grew to become larger offspring - offspring from $21^{\circ} \mathrm{C}$ mothers were larger than offspring of $17^{\circ} \mathrm{C}$ mothers overall - indicating that the TGP benefits on offspring growth were not egg size-mediated despite the occurrence of egg size plasticity. Paternal TGP benefits on offspring growth may have played a role (see also Crean et al., 2013; Shama \& Wegner, 2014), since offspring grew better in their respective paternal environment (at 60 days), especially at elevated temperature. Acclimation to elevated temperature has been shown to influence plasticity of sperm phenotype (Adriaenssens et al., 2012), and methylomes - DNA methylation patterns that can regulate gene expression - are paternally inherited, as recently demonstrated in zebra fish (Jiang et al., 2013). Still, the mechanism(s) underlying the larger sizes of offspring from mothers that developed at $21{ }^{\circ} \mathrm{C}$ remain unclear, and further studies are needed to determine if plasticity of mitochondrial respiration (Shama et al., 2014) and/or other epigenetic marks that affect genes associated with thermal tolerance (Herman et al., 2014) underlie the TGP benefits on mean offspring size.

Similar to the pattern for egg size, offspring of variable environment mothers were smaller but more variable in size than offspring from constant environment mothers, particularly at elevated temperature. In terms of mean size, offspring of 21var mothers suffered most when reared in the nonmatching environment of their mothers $\left(17^{\circ} \mathrm{C}\right)$, indicating that TGP benefits at $21^{\circ} \mathrm{C}$ may have offset some of the losses in mean offspring size in the unpredictable environment. In terms of increased variance in offspring size, it is likely that the effects of diversification employed at reproduction persisted into later developmental and growth stages. That the strength of these effects increased over time, especially under a warming ocean scenario, possibly indicates different mechanisms of response operating over different time spans or life history stages (see also Furness et al., 2015). For instance, offspring of mothers exposed to both stressors (21var) had higher CVs of body size regardless of rearing temperature, whereas offspring of 17var mothers had higher CVs only when reared at $21{ }^{\circ} \mathrm{C}$, indicating that the phenotypic variance resulting from possible bet hedging at reproduction by 17 var mothers was only expressed under stressful conditions (Herman et al., 2014). By rearing split-clutches of offspring in different environments, the test of expression of trait variance used here was actually a test of plasticity of the expression of variance. In other words, for classical bet hedging, one would expect the expression of trait variance regardless of rearing environment. The fact that variance was higher at elevated temperature indicates context-dependent expression of variance, that is, plastic expression of variance, and may be more consistent with the idea of plastic finetuning of a bet-hedging strategy (see also Sadeh et al., 2009; Furness et al., 2015), whereby responses to both maternal and offspring environments interact, resulting in a combination of diversification (by mothers) and plasticity (by offspring).

Since climate change is expected to bring an increase in environmental variability (IPCC 2012), the likelihood that populations will persist under these conditions may depend on the evolution of bet hedging (Simons, 2011). Here, stickleback mothers exposed to variable environments may have spread the risk of future environment uncertainty by producing a range of offspring sizes. At the same time, mothers exposed to predictable, but elevated temperatures primed their offspring via TGP to grow better under warmer conditions. When both predictable and unpredictable environmental variance influence offspring phenotype, and hence, fitness, both plasticity and bet hedging are expected to evolve, and diversified bet hedging may 
occur around the norm of reaction as suggested here (Simons, 2011; Furness et al., 2015). In this study, when the environmental cue was applied was critical in determining its effects. For instance, mean egg size 'decisions' by mothers likely developed based on lifetime or possibly early-life exposure (Donelson et al., 2012; Burton \& Metcalfe, 2014; Shama \& Wegner, 2014), whereas the diversification of egg sizes resulted from the cue of environmental variability experienced only during reproductive conditioning. That is, egg size plasticity leading to a mean egg size that is appropriate for future environmental conditions is likely established at an early developmental stage (constant environment at this time point), but is fine-tuned later during reproductive conditioning to account for environmental variability.

Striking a balance between adaptive plasticity and bet hedging in a warming and increasingly variable climate will be necessary to optimize fitness as environmental conditions change (Simons, 2011, 2014). Here, stickleback mothers responded differently depending on whether warming alone, or warming in conjunction with increased climate variability occurred (Vasseur et al., 2014). With warming alone, offspring size decreased, but TGP benefits offset some of the size losses resulting in partial size compensation. Smaller size at elevated temperature is a common finding in climate change studies (Daufresne et al., 2009), but may or may not reduce fitness, as discussed above. With gradual increases to the mean temperature, many species, especially those at mid-latitudes, are expected to benefit due to lengthening of the growing season. On the other hand, increased variability could counteract any benefits due to greater magnitudes and durations of heat waves (Vasseur et al., 2014). In this study, the effects of possible bet hedging at reproduction on offspring size were exacerbated by warming, that is, variance was more strongly expressed at $21^{\circ} \mathrm{C}$. Here again, TGP benefits at $21^{\circ} \mathrm{C}$ offset some of the losses in offspring size in the variable environment. With only increased climate variability (17var), there was less change to mean offspring size, but context-dependent expression of variance depending on the environment offspring ultimately experienced. A greater understanding of the roles of both TGP and bet hedging will be crucial for predicting how populations will respond to climate change, and if these strategies are sufficient to buffer the ecological and evolutionary implications of warming and increasing climate variability (Crean \& Marshall, 2009; Gremer \& Venable, 2014).

\section{Acknowledgements}

Many thanks to Kaibil Escobar Wolf for taking care of the fish, and to all members of the Coastal Ecological Genetics group for feeding fish on weekends. The manuscript was greatly improved by comments from K. M. Wegner and two anonymous reviewers, and helpful statistical advice from U. Steiner. This study was conducted in accordance with German animal welfare standards (permit no. V312-72241.123-16), and the author has no conflict of interest to declare. LNSS is funded from a DFG (Deutsche Forschungsgemeinschaft) Emmy Noether grant (WE4641/1-1).

\section{References}

Adriaenssens B, van Damme R, Seebacher F, Wilson RS (2012) Sex cells in changing environments: can organisms adjust the physiological function of gametes to different temperatures? Global Change Biology, 18, 1797-1803.

Bonduriansky R, Crean AJ, Day T (2012) The implications of nongenetic inheritance for evolution in changing environments. Evolutionary Applications, 5, 192-201.

Bownds C, Wilson R, Marshall DJ (2010) Why do colder mothers produce larger eggs? An optimality approach. Journal of Experimental Biology, 213, 3796-3801.

Burgess SC, Marshall DJ (2011) Temperature-induced maternal effects and environmental predictability. Journal of Experimental Biology, 214, 2329-2336.

Burgess SC, Marshall DJ (2014) Adaptive parental effects: the importance of estimating environmental predictability and offspring fitness appropriately. Oikos, 123, 769-776.

Burton T, Metcalfe NB (2014) Can environmental conditions experienced in early life influence future generations? Proceedings of the Royal Society B: Biological Sciences, 281, 20140311.

Charmantier A, Garant D (2005) Environmental quality and evolutionary potential: lessons from wild populations. Proceedings of the Royal Society B: Biological Sciences, 272, 1415-1425.

Chevin L, Lande R, Mace GM (2010) Adaptation, plasticity and extinction in a changing environment: towards a predictive theory. Plos Biology, 8, e1000357.

Cohen D (1966) Optimizing reproduction in a randomly varying environment. Journal of Theoretical Biology, 12, 119-129.

Cohen J (1988) Statistical Power Analysis for the Behavioral Sciences (2nd edn). Lawrence Erlbaum Associates, Publishers, Mahwah, NJ, USA.

Crean AJ, Marshall DJ (2009) Coping with environmental uncertainty: dynamic bet hedging as a maternal effect. Philosophical Transactions of the Royal Society B: Biological Sciences, 364, 1087-1096.

Crean AJ, Dwyer JM, Marshall DJ (2013) Adaptive paternal effects? Experimental evidence that the paternal environment affects offspring performance. Ecology, 94, 2575-2582.

Daufresne M, Lengfeller K, Sommer U (2009) Global warming benefits the small in aquatic ecosystems. Proceedings of the National Academy of Sciences, 106, 1278812793.

Donelson JM, Munday PL, McCormick MI, Pitcher CR (2012) Rapid transgenerational acclimation of a tropical reef fish to climate change. Nature Climate Change, 2, 30-32.

Dufresne F, FitzGerald GJ, Lachance S (1990) Age and size-related differences in reproductive success and reproductive cost in threespine stickleback. Behavioral Ecology, 1, 140-147.

Einum S, Fleming IA (2004) Environmental unpredictability and offspring size: conservative vs. diversified bet-hedging. Evolutionary Ecology Research , 6, 443-455.

Fischer B, Taborsky B, Kokko H (2011) How to balance the offspring quantity-quality tradeoff when environmental cues are unreliable. Oikos, 120, 258-270.

Furness AI, Lee K, Reznick DN (2015) Adaptation in a variable environment: phenotypic plasticity and bet-hedging during egg diapause and hatching in an annual killifish. Evolution, 69, 1461-1475.

Galloway LF, Etterson JR (2007) Transgenerational plasticity is adaptive in the wild. Science, 318, 1134-1136.

Garcia-Roger EM, Serra M, Carmona MJ (2014) Bet-hedging in diapausing egg hatching of temporary rotifer populations - a review of models and new insights. International Review of Hydrobiology, 99, 96-106.

Graham JK, Smith ML, Simons AM (2014) Experimental evolution of bet hedging under manipulated environmental uncertainty in Neurospora crassa. Proceedings of the Royal Society B: Biological Sciences, 281, 20140706.

Gremer JR, Venable DL (2014) Bet hedging in desert winter annual plants: optimal germination strategies in a variable environment. Ecology Letters, 17, 380-387.

Halpern SL (2005) Sources and consequences of seed size variation in Lupinus perennis (Fabaceae): adaptive and non-adaptive hypotheses. American Journal of Botany, 92, 205-213. 
Heath DD, Blouw DM (1998) Are maternal effects in fish adaptive or merely physiological side effects? In: Maternal Effects as Adaptations (eds Mousseau TA, Fox CW), pp. 178-201. Oxford University Press, Oxford.

Hendry AP, Day T (2003) Revisiting the positive correlation between female size and egg size. Evolutionary Ecology Research, 5, 421-429.

Herman JJ, Spencer HG, Donohue K, Sultan SE (2014) How stable "should" epigenetic modifications be? Insights from adaptive plasticity and bet hedging. Evolution, 68, 632-643.

IPCC (2012) Managing the risks of extreme events and disasters to advance climate change adaptation. In: A Special Report of Working Groups I and II of the Intergovernmental Panel on Climate Change (eds Field CB, Barros V, Stocker TF et al.), Cambridge University Press, Cambridge, NY, USA.

Jiang L, Zhang J, Wang J-J et al. (2013) Sperm, but not oocyte, DNA methylome is inherited by zebrafish early embryos. Cell, 153, 773-784.

Kaplan RH (1992) Greater maternal investment can decrease offspring survival in the frog Bombina orientalis. Ecology, 73, 280-288.

Kolm N, Ahnesjö I (2005) Do egg size and parental care coevolve in fishes? Journal of Fish Biology, 66, 1499-1515.

Legendre P, Legendre L (1998) Numerical Ecology. Elsevier, New York, NY, USA.

Liefting M, Weerenbeck M, van Dooremalen C, Ellers J (2010) Temperature-induced plasticity in egg size and resistance of eggs to temperature stress in a soil arthropod. Functional Ecology, 24, 1291-1298.

Manenti T, Sorenson JG, Moghadam NN, Loeschcke V (2014) Predictability rather than amplitude of temperature fluctuations determine stress resistance in a natural population of Drosophila simulans. Journal of Evolutionary Biology, 27, 2113-2122.

Marshall DJ, Uller T (2007) When is a maternal effect adaptive? Oikos, 116, 1957-1963.

Marshall DJ, Boduriansky R, Bussiere LF (2008) Offspring size variation within broods as a bet-hedging strategy in unpredictable environments. Ecology, 89, 2506-2517.

Morrongiello JR, Bond NR, Crook DA, Wong BBM (2012) Spatial variation in egg size and egg number reflects trade-offs and bet-hedging in a freshwater fish. Journal of Animal Ecology, 81, 806-817.

Mousseau TA, Fox CW (1998) The adaptive significance of maternal effects. Trends in Ecology and Evolution, 13, 403-407.

Munday PL (2014) Traansgenerational acclimation of fishes to climate change and ocean acidification. F1000prime Reports, 6, 99.

Munday PL, Warner RR, Monro K, Pandolfi JM, Marshall DJ (2013) Predicting evolutionary responses to climate change in the sea. Ecology Letters, 16, 1488-1500.

Olofsson H, Ripa J, Jonzen N (2009) Bet-hedging as an evolutionary game: the tradeoff between egg size and number. Proceedings of the Royal Society B: Biological Sciences, 276, 2963-2969.

Philippi T, Seger J (1989) Hedging one's evolutionary bets, revisited. Trends in Ecology and Evolution, 4, 41-44

R Development Core Team (2011) R: A Language and Environment for Statistical Computing. R Foundation for Statistical Computing, Vienna, Austria. ISBN 3-90005107-0, URL http://www.R-project.org/.

Ramler D, Mitteroecker P, Shama LNS, Wegner KM, Ahnelt H (2014) Non-linear effects of temperature on body form and developmental canalization in the threespine stickleback. Journal of Evolutionary Biology, 27, 497-507.

Räsänen K, Kruuk LEB (2007) Maternal effects and evolution at ecological time scales. Functional Ecology, 21, 408-421.

Sadeh A, Guterman H, Gersani M, Ovadia O (2009) Plastic bet-hedging in an amphicarpic annual: an integrated strategy under variable conditions. Evolutionary Ecology, 23, 373-388.

Salinas S, Brown SC, Mangel M, Munch SB (2013) Non-genetic inheritance and changing environments. Non-Genetic Inheritance, 1, 38-50.
Schade FM, Shama LNS, Wegner KM (2014) Impact of thermal stress on evolutionary trajectories of pathogen resistance in three-spined stickleback (Gasterosteus aculeatus). BMC Evolutionary Biology, 14, 164.

Seger J, Brockmann HJ (1987) What is bet-hedging? Oxford Surveys in Evolutionary Biology, 4, 182-211.

Shama LNS, Wegner KM (2014) Grandparental effects in marine sticklebacks: transgenerational plasticity across multiple generations. Journal of Evolutionary Biology, 27, 2297-2307.

Shama LNS, Strobel A, Mark FC, Wegner KM (2014) Transgenerational plasticity in marine sticklebacks: maternal effects mediate impacts of a warming ocean. Functional Ecology, 28, 1482-1493.

Sheppard C (2004) Sea surface temperature 1871-2099 in 14 cells around the United Kingdom. Marine Pollution Bulletin, 49, 12-16.

Simons AM (2011) Modes of response to environmental change and the elusive evidence for bet hedging. Proceedings of the Royal Society B: Biological Sciences, 278, $1601-1609$.

Simons AM (2014) Playing smart vs. playing safe: the joint expression of phenotypic plasticity and potential bet hedging across and within thermal environments. Journal of Evolutionary Biology, 27, 1047-1056.

Slatkin M (1974) Hedging ones evolutionary bets. Nature, 250, 704-705.

Smith CC, Fretwell SD (1974) Optimal balance between size and number of offspring. American Naturalist, 108, 499-506.

Sunday JM, Calosi P, Dupont S, Munday PL, Stillman JH, Reusch TBH (2014) Evolution in an acidifying ocean. Trends in Ecology and Evolution, 29, 117-125.

Thornton PK, Ericksen PJ, Herrero M, Challinor AJ (2014) Climate variability and vulnerability to climate change: a review. Global Change Biology, 20, 3313 3328.

Vasseur DA, DeLong JP, Gilbert B et al. (2014) Increased temperature variation poses a greater risk to species than climate warming. Proceedings of the Royal Society B Biological Sciences, 281, doi:10.1098/rspb.2013.2612

Via S (1993) Adaptive phenotypic plasticity-target or by-product of selection in a variable environment. American Naturalist, 142, 352-365.

\section{Supporting Information}

Additional Supporting Information may be found in the online version of this article:

Figure S1. Relationship between density and body size (measured as standard length $\pm 0.01 \mathrm{~mm}$ ) for Gasterosteus aculeatus offspring reared at $17{ }^{\circ} \mathrm{C}$ (open symbols; dashed lines) and $21^{\circ} \mathrm{C}$ (closed symbols; solid lines) at (a) 30 days, (b) 60 days and (c) 90 days posthatch.

Table S1. Linear mixed effects models for Gasterosteus aculeatus coefficient of variation (CV) of body size at 30, 60 and 90 days posthatch depicting the influence of offspring rearing temperature (offspring ${ }^{\circ} \mathrm{C}$ ), parental developmental temperatures ( $\mathrm{dam}{ }^{\circ} \mathrm{C}$, sire ${ }^{\circ} \mathrm{C}$ ) and maternal environment predictability (predictability). 